\title{
Sociodemographic Profile of Elderly People with Temporomandibular Disorder and Depression in Combination with Parkinson's Disease
}

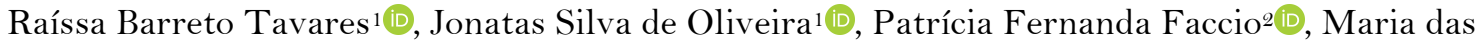 \\ Graças Wanderley de Sales Coriolano²(D, Nadja Maria Jorge Asano², Carla Cabral dos Santos

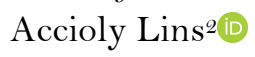

${ }^{1}$ Departament of Dentistry, Federal University of Pernambuco, Recife, PE, Brazil.

${ }^{2}$ Graduate Program in Gerontology, Federal University of Pernambuco, Recife, PE, Brazil.

Correspondence: Raíssa Barreto Tavares, Estrada do Bongi, 1130, Prado, Recife, PE, Brazil. 50830-260. E-mail: raia.b.tavares@gmail.com

Academic Editor: Alessandro Leite Cavalcanti

Received: 20 July 2020 / Review: 24 August 2020 / Accepted: 03 September 2020

How to cite: Tavares RB, Oliveira JS, Faccio PF, Coriolano MGWS, Asano NMJ, Lins CCSA. Sociodemographic profile of elderly people with temporomandibular disorder and depression in combination with Parkinson's disease. Pesqui Bras Odontopediatria Clín Integr. 2021; 21:e0169. https://doi.org/10.1590/pboci.2021.026

\begin{abstract}
Objective: To describe the sociodemographic profile of elderly people with temporomandibular disorder and depression in Parkinson's disease cases. Material and Methods: It is a cross-sectional cohort cut study, which used secondary data from 124 elderly people with Parkinson's disease (PD). To diagnose temporomandibular disorder (TMD), the Research Diagnostic Criteria for Temporomandibular Disorders (RDC/TMD) questionnaire was used, and the variables studied were: age, sex, race, education, marital status, family income, stage of the disease, and depression. The statistical analysis performed was descriptive and used absolute numbers and a frequency count. Results: After the application of the eligibility criteria, the patient records of 81 elderly people with Parkinson's disease were selected; 15 presented associated TMD and depression. The average age was 69 years old; $66.67 \%$ were male; $46.67 \%$ had more than 9 years of schooling; $60 \%$ were married or had a partner; $53.33 \%$ received between 1 and 2 minimum wages; $33.33 \%$ stated they were brown; $80 \%$ were in the moderate stage of the disease; $46.66 \%$ were in group II according to the RDC/TMD, presenting disk displacement; and 53.33\% presented severe depression. Conclusion: It was verified that the elderly people with Parkinson's and associated TMD and depression were male, married or with a partner, on a low income, with nine or more years of schooling, and were in the moderate stage of the disease.
\end{abstract}

Keywords: Parkinsonian Disorders; Temporomandibular Joint Disorders; Behavioral Symptoms. 


\section{Introduction}

Due to decreasing fertility rates and increasing life expectancy, population aging has become more culturally, socially, and politically relevant. With the natural biological aging process of human beings, many difficulties affect elderly individuals, such as the appearance of functional disabilities associated with chronic and degenerative diseases, including Parkinson's disease (PD) [1].

PD is associated with the slow loss of dopaminergic neurons, which causes a reduction in voluntary movements, giving rise to motor symptoms, such as resting tremors, bradykinesia, muscular rigidity, and postural instability [2]. Its systemic influences can generate facial manifestations, promoting undesirable jaw movements, the absence of certain facial expressions, and orofacial tremors, sometimes resulting in pain, a significant characteristic for diagnosing temporomandibular disorder (TMD) [3].

TMD is a pathological condition initially identified by the presence of signs and symptoms accompanied or not by pain, such as cracking or popping joints and difficulty in making jaw movements [4,5]. These can result from emotional instabilities typical of situations of stress, anxiety, or depression, which lead to greater functional demand on the masticatory muscles $[6,7]$.

Depression is a psychosocial disorder that impacts the individual's routine, where it is possible to observe a loss of interest in activities, despondency, and negative thoughts [8]. It can often be linked to the social process of aging and is aggravated when there is a chronic-degenerative or disabling disease associated with PD [9,10]. The depressive symptoms are attributed to the limitations on daily activities and consequent reduction in quality of life $[11,12]$.

A recent study indicated that the prevalence of people with Parkinson's disease and TMD is 35\% and that some of the factors associated with TMD in elderly people were: being female, having a low income, experiencing humming, dizziness, depression, headaches, or bruxism; having reduced number of teeth; and total prostheses $[13,14]$. Due to the lack of information within this theme, we proposed to describe the social demographic profile of elderly people with temporomandibular dysfunction and depression along with Parkinson's disease, aiming to discover the most frequent clinical diagnosis of TMD, thus helping to provide more information in this field of aging for future studies.

\section{Material and Methods}

Study Design

It is a cross-sectional study, which used a secondary data source from a study carried out at the Clinical Hospital of the Federal University of Pernambuco in the period from January to August of 2018, involving 124 elderly people with Parkinson's disease.

The eligibility criteria for inclusion in the study were patients that: 1) presented a clinical diagnosis of idiopathic PD and were in stages 1 (mild disability), 2, or 3 (moderate disability) of the global scale for classifying PD according to Hoehn \& Yahr (HY) [15];2) were under the effect of an anti-Parkinson's drug ("on” phase); 3) had natural teeth or used partial/total dental prostheses or a fixed prosthesis; and 4) were oriented people with preserved autonomy.

The exclusion criteria were: 1) the presence of another associated neurological disease; 2) a history of facial or mandibular trauma; 3) cognitive impairment evaluated by the Mini-Mental State Examination (MMSE) [16]; 4) people with no teeth in one of the dental arches or in both and/or with no prosthesis; 5) a history of surgery for the treatment of PD; and 6) impaired verbal communication. 


\section{Data Collection}

The cognitive screening was carried out using the MMSE. This is a test that contains 19 questions, with a maximum score of 30 , with activities in the areas of temporal and spatial orientation, immediate memory, attention and calculation, evocation, and language. For every correct answer, a pre-established score is given. Educational level was classified according to the participant's total score in relation to the cut-off scores pre-established by the MMSE: illiterate (O years) - cut-off score of 18; low education (1 to 3 incomplete years) - cut-off score of 21 ; medium education (4 to 7 incomplete years) - cut-off score of 24 ; high education (8 or more years) - cut-off score of 26 . For classification purposes, the educational level reached according to the aforementioned cut-off score was observed [17].

The independent variables were characterized as follows: age according to the age groups 60 to 69,70 to 79 , and 80 to 89 years old; female or male sex; education divided into illiterate (o years of schooling), low (14 years of schooling), medium (5-8 years of schooling), high (9 or more); marital status divided into married or with a partner, separated or divorced, widow(er), and single; family income divided into less than 1,1 to 2,3 to 4, or 5 minimum wages; color or race divided into black, white, yellow, brown, or other; and stage of PD divided into mild (1) or moderate (2 and 3 ).

To evaluate TMD and depression, the Brazilian version of the Research Diagnostic Criteria for Temporomandibular Disorder (RDC/TMD) [18] was used, which is considered the gold standard for this type of evaluation and is composed of two axes: axis I, which enables the measurement of physical findings and is composed of an intra and extraoral clinical exam (jaw movements, sounds and palpation of the temporomandibular joint (TMJ) and masticatory muscles); and axis II, which enables an evaluation of a psychosocial nature, consisting of 31 questions. The data obtained enable the individuals to be classified into three diagnostic groups: I) Muscular diagnostics (the presence of myofascial pain with or without limitation of the mouth opening); II) Disk displacement (disk displacement with reduction, disk displacement without reduction with a limited opening, and disk displacement without reduction and without limited opening); III) Arthralgia, arthritis, arthrosis (arthralgia, osteoarthritis, and osteoarthrosis of the TMJ). A single individual can present only one or multiple diagnoses [19]. For diagnosing depression, the 32 items that compose aspect 20 of axis II were evaluated, in which depending on the result, the individual can be classified as normal (result below 0.535), presence of moderate depression (result above 0.535 and below 1.105), and severe depression (result above 1.105) [20].

The data collection was performed by two examiners, one dental surgeon and a-one physiotherapist, previously trained to ensure uniformity in the data collection. The first researcher was responsible for the clinical diagnosis of TMD through RDC/TMD.

\section{Descriptive Analysis of the Data}

The data collected were stored in an Excel spreadsheet, using descriptive statistics, compiled in absolute numbers and with a frequency count to characterize the sample. The sample was stratified according to the diagnosis of the presence or not of TMD, depression, and the following clinical variables: age, sex, education, marital status, income, color or race, and stage of PD.

\section{Ethical Clearance}

This study was approved by the Human Research Ethics Committee of the Federal University of Pernambuco, via consolidated opinion CAAE: 14381819.0.0000.5208. 


\section{Results}

After applying the eligibility criteria, 81 elderly patients with Parkinson's were chosen from the database. Of these, 15 individuals presented associated TMD and depression (Figure 1). Table 1 presents the sociodemographic profile of the sample and the stages of the disease. The age varied from 60 to 89 years old, with a mean of 69 years old; $66.67 \%$ were male; $46.67 \%$ indicated having nine or more years of schooling; $60 \%$ stated they were married or with a partner; around 54\% communicated that they received from 1 to 2 minimum wages; $33 \%$ declared themselves to be brown; and most belonged to stages 2 and 3 of the disease, considered moderate for PD.

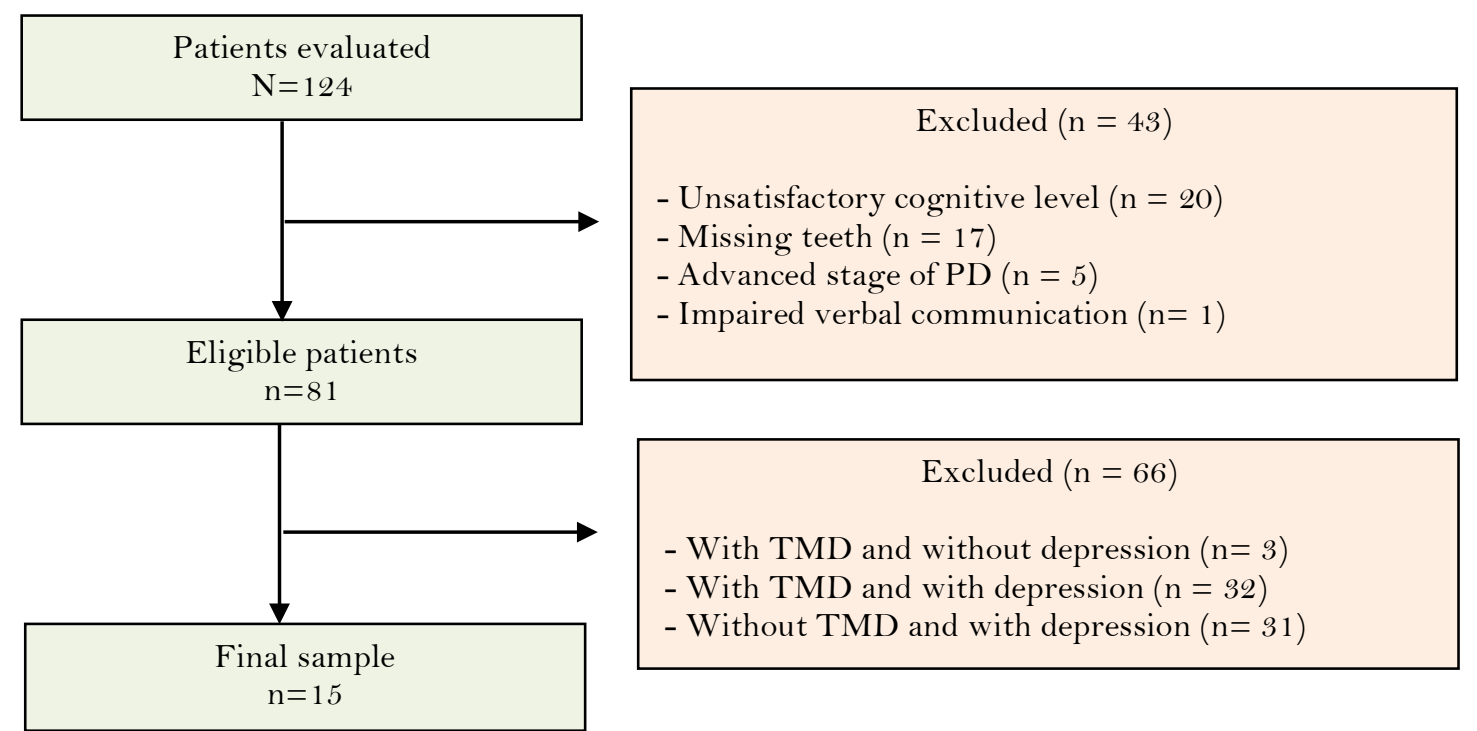

Figure 1. Study flowchart for choosing the final sample.

Table 1. Sociodemographic characteristics of the sample and stage of Parkinson's disease.

\begin{tabular}{|c|c|c|}
\hline Variables & $\mathrm{N}$ & $\%$ \\
\hline \multicolumn{3}{|l|}{ Age (Years) } \\
\hline $60-69$ & 7 & 46.67 \\
\hline $70-79$ & 7 & 46.67 \\
\hline $80-89$ & 1 & 6.66 \\
\hline \multicolumn{3}{|l|}{ Sex } \\
\hline Female & 5 & 33.33 \\
\hline Male & 10 & 66.67 \\
\hline \multicolumn{3}{|l|}{ Education } \\
\hline Illiterate $(0)$ & 1 & 6.66 \\
\hline Low (1-4) & 4 & 26.67 \\
\hline Medium (5-8) & 3 & 20.0 \\
\hline High (9 or more) & 7 & 46.67 \\
\hline \multicolumn{3}{|l|}{ Marital Status } \\
\hline Married or has a Partner & 9 & 60.0 \\
\hline Separated or Divorced & 2 & 13.34 \\
\hline Widow(er) & 3 & 20.0 \\
\hline Single & 1 & 6.66 \\
\hline \multicolumn{3}{|l|}{ Family Income (MW)* } \\
\hline Less than 1 & 2 & 13.34 \\
\hline $1-2$ & 8 & 53.33 \\
\hline $3-4$ & 4 & 26.67 \\
\hline $5-10$ & 1 & 6.66 \\
\hline
\end{tabular}




\begin{tabular}{|lcc} 
Black & 4 & 26.67 \\
White & 4 & 26.67 \\
Yellow & 1 & 6.66 \\
Brown & 5 & 33.33 \\
Other & 1 & 6.66 \\
Stage of the Disease & 3 & 20.0 \\
Mild (1) & 12 & 80.0 \\
Moderate (2 and 3) & & \\
\hline *MW
\end{tabular}

*MW = minimum wage in effect in 2018: $\mathrm{R} \$ 954.00$.

Figure 2 shows that most of the sample (46.66\%) fit into MTD diagnostic group II, according to the RDC/TMD. In Table 2 , it can be observed that 8 of the 15 individuals studied presented severe depression and that the elderly individuals categorized into more than one TMD diagnostic group were in a severe state of depression.

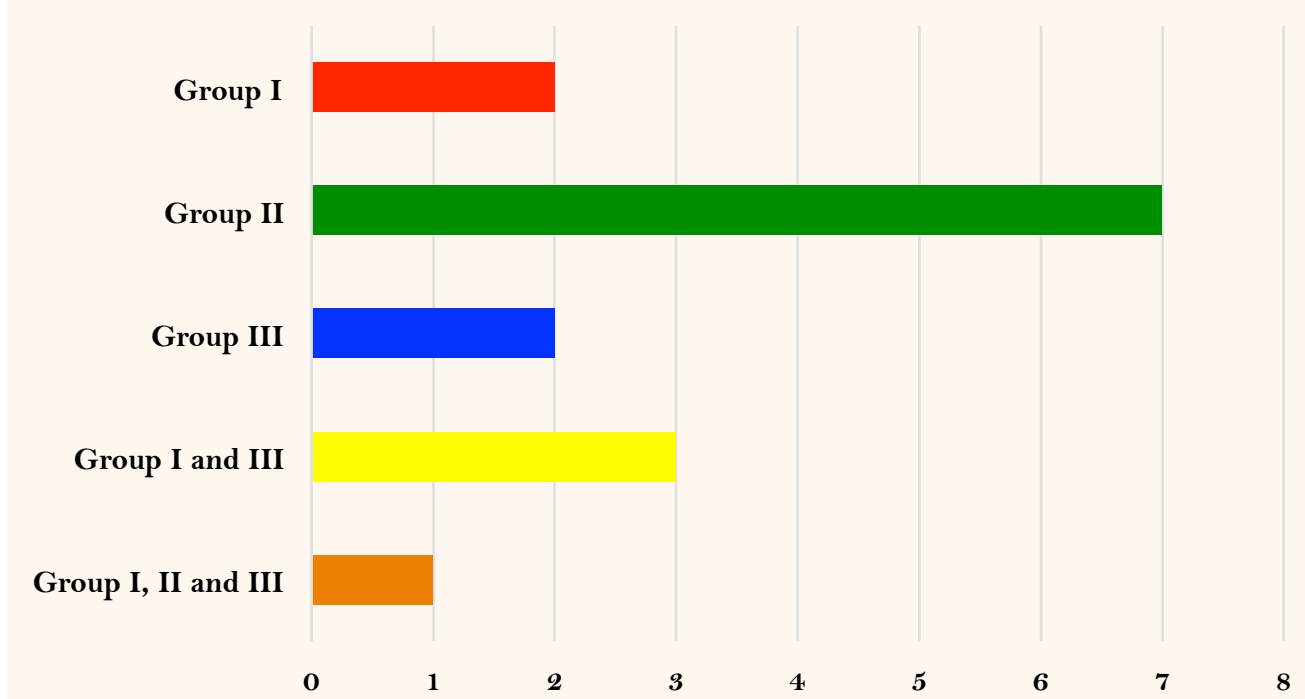

Figure 2. Distribution in number of elderly individuals in accordance with the temporomandibular disorder group according to RDC/TMD.

Table 2. Diagnostic distribution in TMD groups with clinical depression.

\begin{tabular}{lcc}
\hline \multicolumn{1}{c}{ TMD Diagnostic Groups } & Moderate Depression & Severe Depression \\
& N & N \\
\hline Group I & 1 & 1 \\
Group II & 5 & 2 \\
Group III & 1 & 1 \\
Groups I and III & 0 & 3 \\
Groups I, II, and III & 0 & 1 \\
\hline
\end{tabular}

\section{Discussion}

This study enabled the observation of a greater prevalence of male individuals with TMD, which can be explained by the fact that the elderly people studied had Parkinson's, and the literature indicates that this disease is more frequent among that sex due to the protection generated by estrogen of the neuronal cells of women [21]. Studies defend the hypothesis that the male-specific gene (SRY of the Y chromosome) triggers the loss of dopamine-secreting neurons [19]. This predominance was also described in the analysis of motor symptoms of Parkinson's disease carried out at a tertiary hospital in Rio de Janeiro, Brazil, in which there was 
a proportion of 2.5 men for every 1 woman in a total of 95 patients [22]. Therefore, this explains the contradiction observed from relating only elderly individuals to TMD or to depression, in which the authors highlighted the prevalence of the female sex in the analyses [3,14,23-25].

When income was evaluated, the prevalence of individuals with 1 to 2 minimum wages was observed, corroborating with another study that found a similar result to that of this one, as well as a study that indicated a significant association between socioeconomic situation and chronic-degenerative diseases, including PD [3,4]. Moreover, in a study conducted by Magalhães et al. [26], in which social classes were analyzed as risk factors for TMD, it was observed that the individuals that expressed more symptoms belonged to classes $\mathrm{D}$ and $\mathrm{E}$.

Another relevant aspect found in this study was that a significant number of elderly people had a high elevated level of schooling. However, this was not consistent with the literature studied, which categorized elementary education first in the statistics for elderly people with Parkinson's [27]. On the other hand, by analyzing studies that have investigated patients with PD associated with TMD, it was possible to find closer results to that observed in this study, with high school being the main educational level [13]. A study conducted to identify depressive symptoms in patients with temporomandibular joint disorders observed that $40 \%$ fit into the incomplete college education category [28].

With relation to race, it was verified that brown color was dominant, similarly to the study conducted in the city of Salvador, Brazil, which sought to describe the clinical-epidemiological profile of people with PD and found that $52.94 \%$ of the individuals fit into that classification [21]. Regarding marital status, there was a higher frequency of married individuals or ones with partners, corroborating a study conducted in the state of Paraná, Brazil, which evaluated patients with muscular and joint disorders with symptoms of depression, in which $49.6 \%$ were married [29]. Concerning the disease stage, the data reported in this research resembles another study conducted in a public university hospital, which found that $79 \%$ of the people evaluated were in stages 2 and 3 of Parkinson's disease, presenting TMD [13].

When we compare the results relating to the TMD diagnosis, these findings corroborate with another study, which presented cracking/popping as the main characteristic for diagnosis group II [13]. In the search for studies that analyzed people with TMD or depression combined with PD, it was verified that studies in this field are scarce in the literature studied. In one study conducted by Bakke et al. [30], it was possible to verify the negative impact of oral health on people in the moderate and advanced stages of the disease. Moreover, Massena and Frasseto [31] highlighted the influence of psychoemotional factors and activities performed daily on TMD's chronic pains. Consequently, Faccio et al. [14] reported depression as a predictor strongly associated with TMD prevalence.

Therefore, the most common emotional state related to chronic pain is depression and the day-to-day activities of someone with PD are compromised due to motor limitations, favoring the presence of PD, depressive symptoms, and TMD [12,32,33]. With this, we suggest more research in this field of activity to collaborate with greater Dentistry knowledge to care for those people.

The limitation of the study was that the people included in the research had to be elderly and have three joint diagnoses - Parkinson's (light and moderate stages), TMD, and depression - at the moment of the data collection, besides having natural teeth or using a prosthesis, which restricted the sample number. As a result, it was not possible to perform statistical analyses among the variables studied that could verify a cause and effect relationship, thus justifying this study's descriptive design. The outlook for the future would be to find a much greater number of subjects with this profile. 


\section{Conclusion}

The sociodemographic profile of elderly people who had Parkinson's and associated TMD and depression were of the male sex, married or with a partner, on a low income, with nine or more years of schooling, and moderate stage of the disease.

\section{Authors' Contributions}

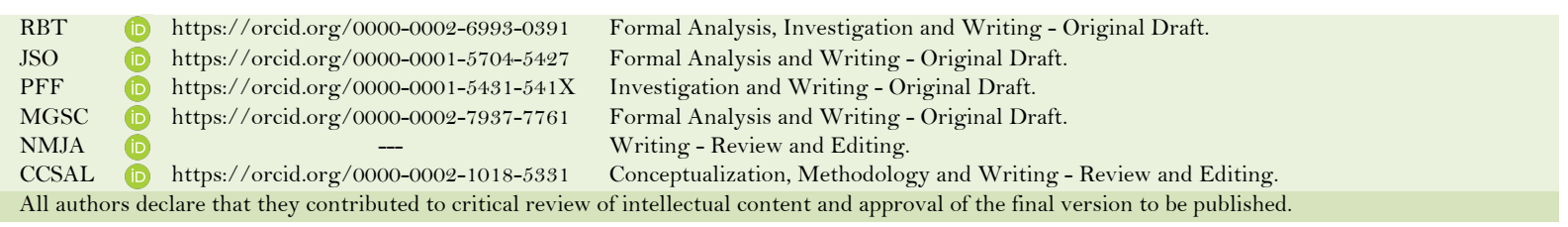

\section{Financial Support}

None.

\section{Conflict of Interest}

The authors declare no conflicts of interest.

\section{Data Availability}

The data used to support the findings of this study can be made available upon request to the corresponding author.

\section{Acknowledgements}

We are grateful to the neurologist Dr. Amdore Guescel Asano, who enabled the realization of this research in the Neurology Outpatient Clinic at the UFPE Clinical Hospital, and to the Scientific Initiation Program (PIBIC/UFPE).

\section{References}

[1] Miranda GMD, Mendes ACG, Silva ALA. Population aging in Brazil: current and future social challenges and consequences. Rev Bras Geriatr Gerontol 2016; 19(3):507-19. https://doi.org/10.1590/1809-98232016019.150140

[Q] Souza CFM, Almeida HCP, Sousa JB, Costa PH, Silveira YSS, Bezerra JCL. Parkinson's disease and the process of aging motor: literature review. Rev Neurocienc 2011; 19(4):718-23. https://doi.org/10.34024/rnc.2011.v 19.8330

[3] Silva TVA, Sobral AV, Silva RM, Almeida VLS, Coriolano MGWS, Lins CCSA. Pain, click and crepitation as factors associated with temporomandibular dysfunction in Parkinson's disease. $\mathrm{Br} \mathrm{J}$ Pain 2018; 1(3):248-54. https://doi.org/10.5935/2595-0118.20180048

[4] Cavalcanti MOA, Lima CCM, Lima JMC, Gomes I, Goldim JR. Prevalence of temporo mandibular dysfunction in non-institutionalized elderly people. Estud Interdiscipl Envelhec 2015; 20(2):551-66.

[5] Albuquerque LCA, Silva HJ, Pernambuco LA, Lima SJH, Cunha DA. Amplitude and speed of masticatory movements in patients with Parkinson's disease. Rev CEFAC 2016; 19(1):69-74

https://doi.org/10.1590/1982-021620171919516

[6] Dıraçoğlu D, Yıldırım NK, Saral İ, Özkan M, Karan A, Özkan S, et al. Temporomandibular dysfunction and risk factors for anxiety and depression. J Back Musculoskelet Rehabil 2016; 29(3):487-91.

https://doi.org/10.3233/BMR-150644

[7] Czernaik CM, Muniz FWMG, Colussi PRG, Rosing CK, Colussi EL. Association between temporomandibular disorder symptoms and demographic, dental and behavioral factors in the elderly: a population-based cross-sectional study. Br J Pain 2018; 1(3):223-30. https://doi.org/10.5935/2595-0118.20180044

[8] Selaimen C, Brilhante DP, Grossi ML, Grossi PK. Depression and neuropsychological testing in patients with temporomandibular disorders. Ciênc Saúde Coletiva 2007; 12(6):1629-39. https://doi.org/10.1590/S1413-81232007000600024

[9] Duarte MB, Rego MAV. Depression and clinical illness: comorbidity in a geriatric outpatient clinic. Cad Saúde Pública 2007; 23(3):691-700. https://doi.org/10.1590/So102-311X2007000300027

[10] Stella F, Gobbi S, Corazza DI, Costa JLR. Depression in elderly: diagnostic, treatment and physical activity. Motriz 2002; 8(3):91-8.

[11] Hellwig N, Munhoz TN, Tomasi E. Depressive symptoms among the elderly: a cross-sectional population-based study. Ciênc Saúde Coletiva 2016; 21 (11):3575-84. https://doi.org/10.1590/1413-812320152111.19552015 
[12] Nakabayashi TIK, Chagas MHN, Corrêa ACL, Tumas V, Loureiro SR, Crippa JAS. Prevalence of depression in Parkinson’s disease. Rev Psiq Clín 2008; 35(6):2 19-27. https://doi.org/10.1590/So101-60832008000600003

[13] Silva RM, Santos VL, Silva TVA, Lins CCSA. Prevalence of temporomandibular joint disorder in people with Parkinson's disease in a public university hospital. Rev CEFAC 2019; 21(3):1-10.

https://doi.org/10.1590/1982-0216/201921317618

[14] Faccio PF, Santos MAB, Silva TAM, Moretti EC, Coriolano MGWS, Lins CCSSA. Factors associated with temporomandibular dysfunction in the elderly: an integrative literature review. Rev Bras Geriatr Gerontol 2019; 22(1):1-11. https://doi.org/10.1590/1981-22562019022.180116

[15] Hoehn MM, Yahr MD. Parkisionism: onset, progession, and mortality. Neurology 1967; 17(5):427-42. https://doi.org/10.1212/wnl.17.5.427

[16] Folstein MF, Folstein SE, McHugh PR. "Mini-mental state". A practical method for grading the cognitive state of patients for the clinician. J Psychiatr Res 1975; 12(3):189-98. https://doi.org/10.1016/0022-3956(75)90026-6

[17] Bertolucci PHF, Brucki SMD, Campacci SR, Juliano Y. The Mini-Mental State Examination in an outpatient population: influence of literacy. Arq Neuropsiquiatr 1994; 52(1):1-7. https://doi.org/10.1590/So004-282X1994000100001

[18] Dworkin SF, LeResche L. Research diagnostic criteria for temporomandibular disorders: review, criteria, examinations and specifications, critique. J Craniomandibular Disord 1992; 6(4):301-55.

[19] Lucena LBS, Kosminsky M, Costa LJ, Góes PSA. Validation of the Portuguese version of the RDC/TMD Axis II questionnaire. Braz Oral Res 2006; 20(4):312-17. https://doi.org/10.1590/S1806-83242006000400006

[20] Toledo BAS, Capote TSO, Campos JADB. Association between temporomandibular dysfunction and depression. Cienc Odontol Bras 2008; 11(4):75-9.

[21] Fernandes I, Filho ASA. Estudo clínico-epidemiológico de pacientes com doença de Parkinson em Salvador-Bahia. Rev Neuro Pisiq 2018; 22(1):45-59. [In Portuguese]

[22] Lee PC, Artaud F, Cormier-Dequaire F, Rascol O, Durif F, Derkinderen P, et al. Examining the reserve hypothesis in Parkinson's disease: a longitudinal study. Rev Movement Disorders 2019; 34(11):1663-71. https://doi.org/10.1002/mds.27854

[23] Spitz M, Tinoco V, Menezes F, Pereira JS. Análise dos sintomas motores na doença de Parkinson em pacientes de hospital terciário do Rio de Janeiro. Rev Bras Neurol 2017; 53(3):14-18.

[24] Andrade TNC, Frare JC. Comparative study between the effects of isolated manual therapy techniques and those associated with low level laser therapy on pain in patients with temporomandibular dysfunction. RGO 2008; 56(3):287-95.

[25] Ferrari JF, Dalacorte RR. Use of yesavages geriatric depression scale to evaluate the prevalence of depression in inpatient elderly subjects. Sci Med 2007; 17(1):3-8.

[26] Magalhães BG, Sousa ST, Mello VVC, Barbosa ACS, Morais MPLA, Vasconcelos MMVB, et al. Risk factors for temporomandibular disorder: Binary logistic regression analysis. Med Oral Patol Oral Cir Bucal 2014; 19(3):e232-6. https://doi.org/doi:10.4317/medoral.19434

[27] Martins NIM, Asano NMJ, Lins CCSA, Coriolano MGWS. Demographic and clinical variables as differentiating predictors of cognitive disorders in Parkinson's disease. Rev Bras Geriatr Gerontol 2019; 22(1):1-9. https://doi.org/10.1590/1981-22562019022.180141

[28] Schmidt DR, Ferreira VRT, Wagner MF. Temporomandibular disorder: anxiety, depression and early maladaptive schemas. Temas Psicol 2015; 23(4):973-85. https://doi.org/10.9788/TP2015.4-13

[29] Salles BL, Progiante PS, Marson FC, Silva CO, Ferreira EC. Relation between the signals and symptoms of temporomandibulardysfunction and orofacial pain and your association with thepsychosocial variables. Rev Uningá $2015 ; 24(1): 13-8$.

[30] Bakke M, Larsen SL, Lautrup C, Karlsborg M. Orofacial function and oral health in patients with Parkinson's disease. Eur J Oral Sci 2011; 119(1):27-32. https:///doi.org/10.1111/j.1600-0722.2010.00802.x

[31] Massena P, Frassetto SS. Psychological aspects associated to temporomandibular dysfunction: a systematic review of the literature. Aletheia 2015; (47-48):162-82.

[32] Bove SRK, Guimarães AS, Smith RL. Characterization of patients in a temporomandibular dysfunction and orofacial pain outpatient clinic. Rev Latino-am Enfermagem 2005; 13(5):686-91. https://doi.org/10.1590/S0104-1 1692005000500012

[33] Galhardo MMAMC, Amaral AKFJ, Vieira ACC. Characterizing cognitive disorders in Parkinson's disease. Rev Cefac 2009; 11 (Suppl 2):251-7. https://doi.org/10.1590/S1516-18462009000600015 